\title{
A análise da racionalidade nas organizações - um balanço do desenvolvimento de um campo de estudos no Brasil
}

\author{
Rationality analysis in organizations - the development of a field of studies in Brazil \\ Maurício Serva ${ }^{1}$ \\ Universidade Federal de Santa Catarina / Centro Socioeconômico, Departamento de Ciências da Administração, Florianópolis - SC, Brasil \\ Déris Caitano ${ }^{2}$ \\ Universidade Federal de Santa Catarina / Centro Socioeconômico, Departamento de Ciências da Administração, Florianópolis - SC, Brasil \\ Laís Santos ${ }^{3}$ \\ Universidade Federal de Santa Catarina / Centro Socioeconômico, Departamento de Ciências da Administração, Florianópolis - SC, Brasil \\ Gabriel Siqueira ${ }^{4}$ \\ Universidade Federal de Santa Catarina / Centro Socioeconômico, Departamento de Ciências da Administração, Florianópolis - SC, Brasil
}

\section{Resumo}

Este artigo tem como objetivo apresentar o campo de estudos da racionalidade substantiva nas organizações, impulsionado com a publicação do trabalho de Serva (1997a; 1997b), quando o pesquisador operacionalizou as propostas de Guerreiro Ramos (1981) em um quadro de análise e verificou empiricamente a existência da razão substantiva na prática administrativa. Através da revisão bibliográfica de trinta e oito trabalhos científicos que adotaram o modelo de Serva, buscou-se demonstrar que as pesquisas sobre a racionalidade nas organizações estão em franca expansão, evidenciando o desenvolvimento desse campo de estudos no Brasil. Os trabalhos, classificados em primeira e segunda geração, foram analisados em sua forma integral. Suas principais limitações e contribuições foram sistematicamente aprofundadas. A análise desses resultados possibilitou validar a contribuição do modelo para campo dos estudos organizacionais, reforçando essa linha de pesquisa e apresentando novas possibilidades de pesquisas a partir do pensamento de Guerreiro Ramos.

Palavra-chave: Racionalidade Substantiva. Racionalidade Instrumental. Gestão.

Artigo submetido em 11 de fevereiro de 2014 e aceito para publicação em 11 de julho de 2014.

DOI: http://dx.doi.org/10.1590/1679-395116344

${ }^{1}$ Professor da Universidade Federal de Santa Catarina; Coordenador do Núcleo de Pesquisa em Organizações, Racionalidade e Desenvolvimento; Doutor em Administração pela Escola de Administração de Empresas de São Paulo (EAESP-FGV). Endereço: Universidade Federal de Santa Catarina, Campus Reitor João David Ferreira Lima, CSE - sala 229 - CEP 88040-900, Florianópolis SC, Brasil. E-mail: mserva@pesquisador.cnpq.br

${ }^{2}$ Doutoranda em Administração na Universidade Federal de Santa Catarina; Membro do Núcleo de Pesquisa em Organizações, Racionalidade e Desenvolvimento. Endereço: Universidade Federal de Santa Catarina, Campus Reitor João David Ferreira Lima, CSE - sala 229 - CEP 88040-900, Florianópolis - SC, Brasil. E-mail: derisoliveira@gmail.com

${ }^{3}$ Mestre em Administração pela Universidade Federal de Santa Catarina. Endereço: Universidade Federal de Santa Catarina, Campus Reitor João David Ferreira Lima, CSE - sala 229 - CEP 88040-900, Florianópolis - SC, Brasil. E-mail: lais.ssantos@yahoo.com.br

${ }^{4}$ Mestre em Administração pela Universidade Federal de Santa Catarina; Membro do Núcleo de Pesquisa em Organizações, Racionalidade e Desenvolvimento. Endereço: Universidade Federal de Santa Catarina, Campus Reitor João David Ferreira Lima, CSE - sala 229 - CEP 88040-900, Florianópolis - SC, Brasil. E-mail: gabrielsica@gmail.com 


\begin{abstract}
This article aims to present the field of studies of the substantive rationality in the organizations, improved by the publishing of the research conducted by Serva (1997a; 1997b) that operationalized the proposals of Guerreiro Ramos (1981) by creating a framework of analysis that allowed him to empirically verify the existence of substantive rationality in management practices. Through the bibliographic review of thirty eight scientific studies, we demonstrated the stage of expansion in which the researches of rationality in organizations are at the present, evidencing the development of this field of research in Brazil. The studies were classified into first and second generation, and were fully investigated. The analysis of these results allowed us to validate the contribution of the model to the field of organizational studies, reinforcing this line of research field and presenting new possibilities of research from the thought of Guerreiro Ramos.
\end{abstract}

Keywords: Substantive Rationality. Instrumental Rationality. Management.

\title{
Introdução
}

O presente artigo retoma a discussão iniciada por Serva (1997a; 1997b) quando publicou os resultados de uma pesquisa cujo modelo de análise foi elaborado para evidenciar a concretização da racionalidade substantiva na gestão de organizações produtivas. Na concepção de Serva (1997a; 1997b), os trabalhos realizados a partir da obra de Alberto Guerreiro Ramos, embora muito bem elaborados, até então não tinham demonstrado na prática de organizações reais como a racionalidade substantiva se revelava nas atividades de gestão, gerando uma lacuna nesse campo de estudos. Serva (1997a; 1997b) considerou que a morte de Guerreiro Ramos em 1982, apenas um ano após a publicação de "A Nova Ciência das Organizações", deixou o campo de estudos da racionalidade nas organizações com um impasse por não demonstrar claramente que a razão instrumental não é única a fundamentar práticas de gestão. As pesquisas realizadas se restringiam ao plano conceitual, enquanto a administração é considerada como uma ciência social aplicada e, por conseguinte, a ação é uma dimensão constitutiva que não deve ser esquecida, principalmente pelos estudos de natureza crítica.

$\mathrm{Na}$ tentativa de superar tal impasse, o autor desenvolveu um modelo de análise para nortear seu estudo etnográfico em três empresas situadas em Salvador. Esse modelo apresenta elementos constitutivos das racionalidades instrumental e substantiva que foram analisados conforme se manifestam em onze processos administrativos. Assim, tal formulação apontava para novas possibilidades no campo de estudos organizacionais sobre a temática da racionalidade. Após a publicação dos resultados da pesquisa em revistas brasileiras de administração, o modelo foi replicado ao longo dos últimos dezessete anos por diversos pesquisadores em diferentes organizações situadas em vários estados do Brasil. O exame desses trabalhos consiste no meio específico empregado neste artigo para identificar o estágio atual do campo de estudos sobre a racionalidade na gestão de organizações no Brasil cujo pilar fundamental é o pensamento de Guerreiro Ramos. Porém, para bem fundamentar esse exame, é necessária, antes, uma revisão, ainda que sintética, das origens dos estudos sobre a racionalidade nas ciências sociais, além de identificar os precursores desse tema no estudo das organizações em nosso país.

A discussão em torno do tema da racionalidade não está circunscrita a um campo do conhecimento. Este tema permeia uma série de estudos críticos da modernidade na filosofia, sociologia e nas ciências sociais de maneira geral. Fundamentalmente, é a partir do desenvolvimento da ciência e a supremacia da técnica que a razão assume um caráter único e homogêneo, não ao acaso, mas com o propósito de justificar a base de um sistema de crescimento econômico sem precedentes na história da humanidade. No entanto, tal concepção omitiu a compreensão original do conceito de racionalidade humana, como demonstrado na crítica de diferentes autores da filosofia e da sociologia.

De fato, a crítica à racionalidade instrumental esteve no cerne de uma crítica muito mais ampla ao sistema capitalista, o qual se mostrava em pleno desenvolvimento. De acordo com Chanlat (1996), a crítica ao 
capitalismo foi direcionada a diferentes aspectos do sistema: em Weber pela racionalização, Marx pela acumulação de capital, Polanyi pela hegemonia das categorias econômicas, Dumont pelo individualismo, entre outros. Contudo, é a partir de Weber que se desenvolve toda uma linha crítica de estudos sobre a racionalidade. Em Karl Mannheim, Adorno, Horkheimer e especificamente pelas contribuições da Escola de Frankfurt, se estabelece uma linha crítica ao domínio da razão instrumental (GUERREIRO RAMOS, 1981).

No campo da filosofia, os estudos sobre racionalidade receberam a importante contribuição de Jürgen Habermas, considerado como herdeiro da Escola de Frankfurt. Entretanto, apesar da herança frankfurtiana, o autor demonstra sua discordância com o pessimismo weberiano e também com as concepções marcuseanas da instrumentalidade inexorável do mundo. Por meio da teoria da ação comunicativa, Habermas (1987) explicita sua divergência à dialética do esclarecimento de Adorno e Horkheimer e empreende um diálogo entre a filosofia e as ciências sociais que culmina na teoria dos atos de fala (FREITAG, 1986).

No cenário das ciências sociais no Brasil, Guerreiro Ramos se fundamenta nos pressupostos dos autores supracitados, mas especialmente na obra de Karl Polanyi, para estabelecer uma alternativa à teoria crítica predominante nos estudos sociais (SERVA, 1996).

De acordo com Paes de Paula (2007), sob o legado de Guerreiro Ramos diversos pesquisadores, tais como Ramon Moreira Garcia, Wellington Newton Felix Martins, Maurício Serva, Fernando Guilherme Tenório, procuraram dar continuidade ao trabalho de Ramos, reforçando os estudos organizacionais em uma perspectiva crítica. A esta relação de autores, é possível ainda acrescentar os nomes de Pizza Júnior e Ariston Azevedo. Especificamente, a pesquisa de Serva (1996; 1997a; 1997b) parece estabelecer dentro dos estudos da racionalidade um novo patamar de exploração no campo das organizações, uma vez que assume o desafio de transpor o debate teórico, acompanhando o curso da ação coletiva no interior das organizações e ressaltando a prática administrativa.

Completados dezessete anos da publicação do trabalho desenvolvido por Serva e da replicação do seu modelo de análise por vários pesquisadores, torna-se possível e oportuno empreender um balanço sobre os limites e os avanços que esses esforços trouxeram para os estudos organizacionais no Brasil que se inspiram no pensamento de Guerreiro Ramos. Este é, exatamente, o objetivo principal deste artigo. Para alcançá-lo, neste trabalho optamos por um delineamento descritivo e qualitativo. Duas estratégias de pesquisa foram utilizadas para a coleta de dados, sendo a principal o levantamento bibliográfico das teses e dissertações sobre o tema defendidas no Brasil no período de 1998 a 2013. O levantamento desses trabalhos foi realizado no Portal da Capes, onde foram selecionados estudos publicados na área da administração que contemplavam a temática da racionalidade e que referenciaram o modelo de análise do autor. A segunda estratégia considerou estudos empíricos que não constituíram teses ou dissertações, mas que foram publicados em revistas científicas reconhecidas.

\section{A Racionalidade como Ponto de Partida}

Kant (2005), em sua Crítica à Razão, estabelece a distinção entre a razão técnica e a teórica e fundamenta o trabalho de diversos autores na filosofia e nas ciências sociais. Partindo dos contornos kantianos, Max Weber inicialmente propõe uma compreensão da racionalidade na sociedade em geral como também nas organizações que a compõem. Weber (1974) se contrapõe ao discurso dos naturalistas e estabelece uma crítica à forma como os cientistas sociais da época limitaram o conceito de racionalidade a uma única concepção técnica e utilitarista. Desta forma, ao elaborar a teoria dos tipos de ação social, Weber faz corresponder para cada ação um tipo ideal de racionalidade subjacente (GUERREIRO RAMOS, 1981; WEBER, 1974). Ressaltamos aqui que Weber recorre aos tipos ideais em suas obras com o intuito de oferecer modelos conceituais servindo à compreensão dos processos sociais. Assim, tais modelos, mesmo 
que não sejam verificados em sua totalidade, podem propiciar avanços significativos ao serem comparados com as situações reais vividas pelos atores em suas interações cotidianas.

Kalberg (1980), ao se aprofundar na definição weberiana, explica que a ação racional formal (ou instrumental), a qual compõe a lógica orientadora da ação nas esferas da vida econômica, legal e científica, suplantou no mundo moderno a ação orientada por valores. No entanto, conforme afirma Kalberg (1980), este padrão de racionalização se mostra insuficiente para caracterizar a ação dos indivíduos em seus relacionamentos pessoais, pois somente a racionalidade substantiva permite que a ação humana seja normatizada qualitativamente pelo "eticamente correto". Assim, o indivíduo, sob a influência de uma constelação de valores próprios, racionaliza a partir dessa ética sua ação em todas as esferas da vida (KALBERG, 1980).

Esta definição de racionalidade, partindo da concepção weberiana, é fundamental para compreender o conteúdo da obra "A Nova Ciência das Organizações" de Guerreiro Ramos. De acordo com Guerreiro Ramos (1981), é a partir de Weber que se desenvolve na Escola de Frankfurt, principalmente com Adorno, Horkheimer e Marcuse, toda uma linha de estudos críticos da soberania da razão instrumental na sociedade moderna. Da escola de Frankfurt, Guerreiro Ramos (1981) ainda toma por referência a contribuição de Habermas (1987) e sua teoria da ação comunicativa.

A crítica de Guerreiro Ramos se destacou no campo dos estudos organizacionais por não somente se restringir à crítica em si, mas por também oferecer uma contribuição para o desenvolvimento de uma nova concepção teórica divergente das teorias tradicionais (GUERREIRO RAMOS, 1981), denominada por ele "abordagem substantiva da organização". Esta via aberta pelo autor acaba por assumir um espaço significativo nos estudos organizacionais no Brasil. Para Dellagnelo (2004), a discussão da racionalidade se tornou o ponto de partida para possibilidades de emancipação ou desenvolvimento dos indivíduos dentro das organizações formais. É nesta perspectiva que a obra de Guerreiro Ramos ganhou um significado expressivo no campo da administração, especificamente no que tange aos estudos da racionalidade nas organizações.

\section{Método}

Para alcançar o citado objetivo, optamos por um delineamento descritivo e qualitativo. A fim de analisar a produção acadêmica sobre o tema da racionalidade substantiva nas organizações a partir da publicação do modelo de análise de Serva (1997a;1997b), como foi declarado acima, a principal estratégia utilizada para a coleta de dados foi o levantamento bibliográfico das teses, dissertações e artigos publicados sobre o tema no Brasil no período de 1998 a 2013.

O levantamento das teses e dissertações foi realizado no Portal da Capes, onde foram selecionados estudos publicados na área da administração que contemplavam a temática da racionalidade. Após uma leitura prévia do resumo, os trabalhos foram analisados na íntegra e foram selecionados aqueles que referenciaram o modelo de análise do autor ou o replicaram na pesquisa.

O levantamento bibliográfico de artigos foi realizado em todos os periódicos nacionais classificados no qualis da CAPES como A2 e B1 da área da administração (os dois principais conceitos alcançados por periódicos nacionais nessa área), exceto por aqueles relacionados às áreas que não estão diretamente relacionadas à nossa área de estudo neste trabalho, como finanças, turismo, ciências da informação, contabilidade, biblioteconomia, educação, entre outras. Desta forma, o levantamento compreendeu os seguintes periódicos A2: Revista de Administração Pública - RAP; Revista de Administração de Empresas RAE; Revista de Administração de Empresas Eletrônica; Revista de Administração Contemporânea - RAC; Revista Organizações \& Sociedade - O\&S; Revista Gestão \& Produção; e Brazilian Administration Review - BAR. Classificados como B1, tivemos os seguintes periódicos: Base; Cadernos CRH; Cadernos EBAPE.BR; Civitas: Revista de Ciências Sociais; Faces: Revista de Administração; Gestão \& 
Regionalidade; RAI: Revista de Administração e Inovação; RAM - Revista de Administração Mackenzie; REAd - Revista Eletrônica de Administração; Revista Brasileira de Ciências Sociais; Revista de Administração da UFSM; Revista de administração da Unimep; Revista de Ciências da Administração; Revista de Sociologia e Política; Sociedade e Estado; Teoria \& Sociedade; e Revista Brasileira de Gestão Urbana.

A busca pelas publicações nos periódicos supracitados foi realizada obedecendo aos seguintes critérios: artigos publicados após 1997 e que estivessem indexadas as palavras-chave racionalidade e/ou racionalidade substantiva. Posteriormente, realizou-se uma análise de cada artigo encontrado sob três aspectos: aderência ao tema da racionalidade, referências utilizadas e citação ou menção ao estudo de Serva (1996; 1997a; 1997b).

Diante desses critérios, os artigos, teses e dissertações foram analisados de forma descritiva e qualitativa. Os resultados das dissertações e teses contemplam as diferentes contribuições de cada um desses estudos, os avanços alcançados, as modificações e adaptações ao modelo. Já os resultados da pesquisa realizada em periódicos pretendem oferecer uma dimensão da importância e disseminação do modelo, considerando a referência aos artigos de Serva (1997a; 1997b) em diferentes estudos publicados sobre o tema da racionalidade.

\section{Notas sobre a Elaboração de um Modelo de Análise da Racionalidade na Gestão de Organizações}

Serva (1996; 1997a; 1997b) destacou a contribuição de diferentes estudos elaborados no Brasil que partiam dos pressupostos levantados por Guerreiro Ramos, como os de Garcia (1980), Tenório (1990), Oliveira (1993), Pizza Júnior (1994), Vasconcelos (1993), Caldas (1994) e Barreto (1993). Entretanto, esta contribuição, mesmo sendo significativa, por si só não foi suficiente para fazer com que a obra de Guerreiro Ramos avançasse no sentido de comprovar empiricamente a existência da racionalidade substantiva nas práticas administrativas. Para Serva (1996), a ausência de evidências empíricas da racionalidade substantiva em organizações produtivas comprometeria o avanço da teoria: "Se desejarmos desenvolver a abordagem substantiva das organizações, necessitamos demonstrar claramente o que significa a adoção da razão substantiva nos processos administrativos e examinar a sua influência na dinâmica organizacional" (SERVA, 1996, p. 158).

Visando superar esse problema, ao qual denominou como impasse, Serva (1996) adota a proposição de Barreto (1993) e concatena as ideias de Guerreiro Ramos (1981) e Habermas (1987) em uma perspectiva de complementaridade. A partir da definição dos diferentes tipos de ação racional e seus elementos constituintes, foi empreendido um reagrupamento lógico desses elementos em face de processos organizacionais, estabelecendo assim um modelo de análise da racionalidade nas organizações. Definidas as categorias principais, o autor empreendeu a identificação das unidades de análise em cada categoria, ou seja, as características presentes nestes processos que indicariam o predomínio de uma lógica racional instrumental ou substantiva. O quadro 1 apresenta o modelo na íntegra: 
Quadro 1

Modelo de análise da racionalidade substantiva nas organizações

\begin{tabular}{|c|c|c|}
\hline \multirow{2}{*}{$\begin{array}{c}\text { Processos } \\
\text { Organizacionais }\end{array}$} & \multicolumn{2}{|c|}{ TIPO DE RACIONALIDADE } \\
\hline & Racionalidade Substantiva & Racionalidade instrumental \\
\hline Hierarquia e normas & $\begin{array}{l}\text { Entendimento } \\
\text { Julgamento ético }\end{array}$ & $\begin{array}{l}\text { Fins, desempenho } \\
\text { Estratégia interpessoal }\end{array}$ \\
\hline Valores e objetivos & $\begin{array}{l}\text { Autorrealização } \\
\text { Valores emancipatórios } \\
\text { Julgamento ético }\end{array}$ & $\begin{array}{l}\text { Utilidade } \\
\text { Fins } \\
\text { Rentabilidade }\end{array}$ \\
\hline Tomada de decisão & $\begin{array}{l}\text { Entendimento } \\
\text { Julgamento ético }\end{array}$ & $\begin{array}{l}\text { cálculo, utilidade } \\
\text { Maximização recursos }\end{array}$ \\
\hline Controle & Entendimento & $\begin{array}{l}\text { Maximização recursos } \\
\text { Desempenho } \\
\text { Estratégia interpessoal }\end{array}$ \\
\hline Divisão do trabalho & $\begin{array}{l}\text { Autorrealização } \\
\text { Entendimento } \\
\text { Autonomia }\end{array}$ & $\begin{array}{l}\text { Maximização recursos } \\
\text { Desempenho } \\
\text { Cálculo }\end{array}$ \\
\hline $\begin{array}{l}\text { Comunicação e } \\
\text { Relações interpessoais }\end{array}$ & $\begin{array}{l}\text { Autenticidade } \\
\text { Valores emancipatórios } \\
\text { Autonomia }\end{array}$ & $\begin{array}{l}\text { Desempenho } \\
\text { Exito/Resultados } \\
\text { Estratégia interpessoal }\end{array}$ \\
\hline $\begin{array}{l}\text { Ação social e } \\
\text { Relações ambientais }\end{array}$ & Valores emancipatórios & $\begin{array}{l}\text { Fins } \\
\text { Exxito/Resultados }\end{array}$ \\
\hline $\begin{array}{l}\text { Reflexão sobre } \\
\text { a organização }\end{array}$ & $\begin{array}{l}\text { Julgamento ético } \\
\text { Valores emancipatórios }\end{array}$ & $\begin{array}{l}\text { Desempenho } \\
\text { Fins, rentabilidade }\end{array}$ \\
\hline Conflitos & $\begin{array}{l}\text { Julgamento ético } \\
\text { Autenticidade } \\
\text { Autonomia }\end{array}$ & $\begin{array}{l}\text { Cálculo } \\
\text { Fins } \\
\text { Estratégia interpessoal }\end{array}$ \\
\hline Satisfação individual & $\begin{array}{l}\text { Autorrealização } \\
\text { Autonomia }\end{array}$ & $\begin{array}{l}\text { Fins, Êxito } \\
\text { Desempenho }\end{array}$ \\
\hline Dimensão simbólica & $\begin{array}{l}\text { Autorrealização } \\
\text { Valores emancipatórios }\end{array}$ & $\begin{array}{l}\text { Êxito/Resultados } \\
\text { Utilidade, Desempenho }\end{array}$ \\
\hline
\end{tabular}

Fonte: Serva (1996, p. 339). 
Pela aplicação do instrumento de análise mediante a técnica da observação participante, durante oito meses, em três pequenas empresas situadas na cidade de Salvador, o pesquisador identificou e examinou o tipo de racionalidade predominante em cada uma delas, tornando possível a evidência empírica de racionalidade substantiva na gestão de organizações produtivas. Os resultados da pesquisa de campo não constituem o foco de análise deste artigo, cumpre somente demonstrar aqui que foi possível caracterizar algumas destas organizações como predominantemente substantivas de acordo com a ferramenta analítica criada por aquele autor.

Os resultados da pesquisa, bem como o escopo metodológico delineado pelo autor foram defendidos em sua tese de doutorado na EAESP/FGV em 1996 e publicados sob a forma de artigos na Revista de Administração de Empresas e na Revista de Administração Pública no ano de 1997 (SERVA, 1996; 1997a; 1997b). A publicação do modelo de análise desenvolvido pelo autor despertou em alguns pesquisadores o interesse por verificar empiricamente a existência de organizações produtivas regidas por outra lógica que não a lógica puramente mercantil. Estes estudos que se pautaram pelo modelo de análise de Serva acima sintetizado serão aqui subdivididos em dois grupos distintos: os estudos da primeira e os da segunda geração.

\section{Resultados da Pesquisa}

Os resultados da pesquisa serão apresentados em três sequências: a primeira contempla os resultados classificados como primeira geração de estudos (teses e dissertações) defendidos sobre o tema, a partir da publicação dos artigos de Serva (1997a; 1997b). A segunda sequência apresenta os estudos da segunda geração, os quais tomaram por base os primeiros estudos e avançaram sobre a temática de forma aprofundada. Já a terceira sequência traz um levantamento sobre os artigos publicados nos principais periódicos científicos nacionais da área da administração que utilizaram como referência o estudo de Serva (1997a; 1997b) ou alguns dos estudos das gerações posteriores para desenvolver a discussão em torno da racionalidade nas organizações.

\section{Trabalhos da primeira geração: limites e contribuições para o desenvolvimento de um campo de estudos}

Os estudos da primeira geração ou da primeira etapa buscaram demonstrar de diferentes formas a real possibilidade de utilizar o quadro de análise desenvolvido por Serva (1996), bem como realizaram uma vasta revisão sobre a razão clássica, razão moderna e os estudos organizacionais. No levantamento realizado, foram identificados vinte trabalhos apresentados em Programas de Pós-Graduação stricto sensu brasileiros que compõem aqui o que chamamos de primeira geração, conforme apresentados no quadro 2 a seguir.

Quadro 2

Trabalhos da primeira geração de estudos sobre a racionalidade

\begin{tabular}{|l|l|l|l|}
\hline \multicolumn{1}{|c|}{ AUTOR } & \multicolumn{1}{|c|}{ TíTULO/TIPO } & \multicolumn{1}{c|}{ ORIENTADOR } & \multicolumn{1}{c|}{\begin{tabular}{c}
\multicolumn{1}{c|}{ IES } \\
ANO
\end{tabular}} \\
\hline Wilson Silva da Matta & $\begin{array}{l}\text { Pesquisa da racionalidade no Sistema } \\
\text { Unimed na Bahia }\end{array}$ & $\begin{array}{l}\text { Wellington Newton Felix } \\
\text { Martins }\end{array}$ & $\begin{array}{l}\text { UFBA } \\
1998\end{array}$ \\
\hline $\begin{array}{l}\text { Marcelo Lorence } \\
\text { Fraga }\end{array}$ & $\begin{array}{l}\text { A empresa produtiva e a racionalidade } \\
\text { substantiva }\end{array}$ & $\begin{array}{l}\text { Francisco de Araujo } \\
\text { Santos }\end{array}$ & $\begin{array}{l}\text { UFRGS } \\
2000\end{array}$ \\
\hline
\end{tabular}




\begin{tabular}{|c|c|c|c|}
\hline AUTOR & TÍTULO/TIPO & ORIENTADOR & $\begin{array}{l}\text { IES } \\
\text { ANO }\end{array}$ \\
\hline $\begin{array}{l}\text { Liliane Gnocchi da } \\
\text { Costa Reis }\end{array}$ & $\begin{array}{l}\text { A racionalidade substantiva na avaliação } \\
\text { de ONGs }\end{array}$ & $\begin{array}{l}\text { Fernando Guilherme } \\
\text { Tenório }\end{array}$ & $\begin{array}{l}\text { EBAPE/FGV } \\
2000\end{array}$ \\
\hline Wagner Pinto & $\begin{array}{l}\text { Análise das práticas administrativas de } \\
\text { uma fundação empresarial aberta }\end{array}$ & $\begin{array}{l}\text { Fernando Guilherme } \\
\text { Tenório }\end{array}$ & $\begin{array}{l}\text { FGV/RJ } \\
2001\end{array}$ \\
\hline Marcelo Almeida & $\begin{array}{l}\text { Empresas de economia de comunhão: } \\
\text { possibilidade de valorização da } \\
\text { racionalidade substantiva na organização } \\
\text { econômica }\end{array}$ & Sérgio Proença Leitão & $\begin{array}{l}\text { PUC/RJ } \\
2002\end{array}$ \\
\hline $\begin{array}{l}\text { Simone Bochi } \\
\text { Dorneles }\end{array}$ & Autogestão e racionalidade substantiva & Eloise Dellagnelo & $\begin{array}{l}\text { UFSC } \\
2003\end{array}$ \\
\hline $\begin{array}{l}\text { Daniel Moraes } \\
\text { Pinheiro }\end{array}$ & $\begin{array}{l}\text { Sustentabilidade de ONGs: um estudo de } \\
\text { caso na organização AFECE }\end{array}$ & Maurício Serva & $\begin{array}{l}\text { UFPR } \\
2003\end{array}$ \\
\hline Newton Manoel Lins & $\begin{array}{l}\text { Articulação entre elementos de } \\
\text { racionalidade instrumental e substantiva } \\
\text { nos processos organizacionais da CAAC } \\
\text { Durval Paiva }\end{array}$ & Washington J. de Souza & $\begin{array}{l}\text { UFRN } \\
2004\end{array}$ \\
\hline Rogério Silveira Tonet & $\begin{array}{l}\text { Fenonomias, economia plural e } \\
\text { desenvolvimento local: um estudo na } \\
\text { feira de artesanato do Largo da Ordem } \\
\text { em Curitiba }\end{array}$ & Maurício Serva & $\begin{array}{l}\text { UFPR } \\
2004\end{array}$ \\
\hline Fábio Vizeu Ferreira & $\begin{array}{l}\text { Organizações burocratizadas rumo a } \\
\text { razão comunicativa: o caso de uma } \\
\text { instituição psiquiátrica }\end{array}$ & Maurício Serva & $\begin{array}{l}\text { UFPR } \\
2004\end{array}$ \\
\hline $\begin{array}{l}\text { José Carlos Silva } \\
\text { Valeriano }\end{array}$ & $\begin{array}{l}\text { Racionalidade nas práticas } \\
\text { administrativas de uma cooperativa em } \\
\text { Itabira-MG }\end{array}$ & $\begin{array}{l}\text { Fernando Coutinho } \\
\text { Garcia }\end{array}$ & $\begin{array}{l}\text { FEAD/MG } \\
2006\end{array}$ \\
\hline Daniele Mudrey & $\begin{array}{l}\text { Racionalidades e valores: um estudo em } \\
\text { duas unidades da Rede Uni-Yôga }\end{array}$ & Sérgio Luís Boeira & $\begin{array}{l}\text { UNIVALI } \\
2006\end{array}$ \\
\hline $\begin{array}{l}\text { Marcos Fadanelli } \\
\text { Ramos }\end{array}$ & $\begin{array}{l}\text { Racionalidade nas organizações do } \\
\text { Terceiro Setor: tensões e implicações para } \\
\text { a avaliação de programas sociais }\end{array}$ & Bernardo Kipnis & $\begin{array}{l}\text { UnB } \\
2006\end{array}$ \\
\hline Paulo Gracílio da Silva & $\begin{array}{l}\text { Sustentabilidade social: um estudo de } \\
\text { caso no Mosteiro Monte Carmelo }\end{array}$ & Maurício Serva & $\begin{array}{l}\text { PUC/PR } \\
2007\end{array}$ \\
\hline
\end{tabular}


Cont. Quadro 2

\begin{tabular}{|l|l|l|l|}
\hline \multicolumn{1}{|c|}{ AUTOR } & \multicolumn{1}{|c|}{ TítULO/TIPO } & \multicolumn{1}{c|}{ ORIENTADOR } & \multicolumn{1}{c|}{\begin{tabular}{c}
\multicolumn{1}{c|}{ IES } \\
ANO
\end{tabular}} \\
\hline $\begin{array}{l}\text { Lucinete Aparecida } \\
\text { Nava Hey }\end{array}$ & $\begin{array}{l}\text { A racionalidade instrumental e } \\
\text { substantiva nas práticas de formação do } \\
\text { administrador }\end{array}$ & $\begin{array}{l}\text { Yara Lucia Mazziotti } \\
\text { Bulgacov }\end{array}$ & $\begin{array}{l}\text { UP/PR } \\
2008\end{array}$ \\
\hline Danielle Rodrigues & $\begin{array}{l}\text { A racionalidade nas práticas } \\
\text { administrativas das cooperativas de } \\
\text { trabalho }\end{array}$ & $\begin{array}{l}\text { Fernando Coutinho } \\
\text { Garcia }\end{array}$ & FNH-MG \\
\hline Osório Carvalho Dias & $\begin{array}{l}\text { Racionalidades subjacentes às ações de } \\
\text { responsabilidade social corporativa em } \\
\text { empresas do setor elétrico brasileiro }\end{array}$ & Janann Joslin Medeiros & $\begin{array}{l}\text { UnB } \\
2009\end{array}$ \\
\hline $\begin{array}{l}\text { Silvana Aparecida de } \\
\text { Aguiar }\end{array}$ & $\begin{array}{l}\text { Práticas cooperativas em redes de } \\
\text { economia solidária sob a óptica da ação } \\
\text { comunicativa: o caso da Rede Justa Trama }\end{array}$ & Maria Moreira Faria & $\begin{array}{l}\text { UNIFOR } \\
2009\end{array}$ \\
\hline Fabiana Besen & $\begin{array}{l}\text { As fenonomias e a economia plural: o } \\
\text { olhar da gestão na dimensão territorial }\end{array}$ & Maurício Serva & $\begin{array}{l}\text { UFSC } \\
2010\end{array}$ \\
\hline João Vitor Nunes Leal & $\begin{array}{l}\text { Análise da dinâmica entre racionalidade } \\
\text { instrumental e substantiva na prática } \\
\text { organizacional: estudo de caso no clube } \\
\text { de xadrez de Florianópolis }\end{array}$ & Sérgio Luís Boeira & $\begin{array}{l}\text { UFSC } \\
2013\end{array}$ \\
\hline
\end{tabular}

Fonte: Elaborado pelos autores.

A abrangência da primeira geração de estudos empíricos da racionalidade nas organizações é ampla e diversificada em termos de: tipo de organização adotado como objeto de estudo; setores de atividades aos quais tais organizações se vinculam; eixos e pressupostos teóricos que servem de base para os estudos e complementam a abordagem de Guerreiro Ramos; estratégia metodológica empregada; e processos organizacionais analisados.

Sobre o tipo de organização adotado como objeto dos estudos da primeira geração, é possível observar que foram pesquisadas diversas formas organizacionais, tais como: cooperativas, micro, pequenas, médias e grandes empresas de produtos e serviços, fundações empresariais, associações, grupos de artesãos, instituições psiquiátricas, organizações sem fins lucrativos, entidades de caráter religioso e filantrópico e pequenos agricultores.

Entre os eixos e pressupostos teóricos que servem de base para as pesquisas da primeira geração, figuram campos como: economia de comunhão; economia plural e substantiva; abordagem territorial; desenvolvimento sustentável; desenvolvimento territorial sustentável; responsabilidade social corporativa; gestão de micro e pequenas empresas; gestão do Terceiro Setor; desenvolvimento institucional; cultura organizacional; tomada de decisão; cooperativismo; autogestão, teoria da ação comunicativa; e paradigma da complexidade.

Contribuições metodológicas ao campo de estudos puderam ser constatadas e são concernentes ao uso de técnicas de coleta e à análise dos resultados. Algumas destas técnicas se mostraram eficientes para lidar com a subjetividade inerente às pesquisas sobre o tema. Neste sentido, a análise de conteúdo se mostrou uma ferramenta importante para produzir inferências na análise das falas, indicando incidências em menor e maior proporção de elementos de uma racionalidade ou outra. A maior parte dos estudos assumiu caráter descritivo, na forma de estudo de caso (único ou múltiplos), análises predominantemente qualitativas e a 
coleta de dados realizada por meio de entrevistas, observação participante e análise de documentos. Foram constatados, também, em alguns casos, a adoção de técnicas quantitativas e o uso de análises estatísticas como alternativa para preceder uma segunda geração qualitativa. Esta possibilidade está evidente no estudo de Pinto (2001) quando o autor complementou as análises com os resultados (estatísticos) obtidos pela aplicação de uma escala de valores percebidos pelos funcionários da organização estudada. Entretanto, o uso de métodos quantitativos como única fonte de análises se mostrou limitado e insuficiente para promover conclusões mais profundas. Alguns estudos envolveram técnicas quantitativas, porém apenas de forma complementar, e os resultados não serviram de ponto de partida para conclusões importantes. No entanto, a observação (participante ou não) aliada a uma postura etnográfica para o estudo daquilo que é "fundado essencialmente na análise das interações e do sentido atribuído à ação" (ANDION e SERVA, 2006, p. 174) parece ter sido o caminho mais apropriado para captar elementos que só podem ser percebidos após um período razoável de convivência com a organização.

Entre os processos organizacionais estudados, algumas pesquisas empreenderam a análise completa das onze rubricas (processos organizacionais), conforme Serva realizou originalmente. A maioria dos trabalhos procurou adaptar o modelo à realidade das organizações, suprimindo ou reformulando alguns dos onze processos considerados no modelo original. As adaptações realizadas se mostraram adequadas ao estudo da racionalidade sempre que os objetivos do autor ou o perfil da organização assim justificassem. Essas modificações na forma de inclusão ou supressão de categorias analíticas foram identificadas nos trabalhos de Almeida (2002), Pinheiro (2003), Ferreira (2004), Tonet (2004), Mudrey (2006), Valeriano (2006), Silva (2007), Nava Hey (2008) e Aguiar (2009).

No que concerne à inclusão de novas categorias, três estudos empreenderam acréscimos importantes ao modelo original. O primeiro deles é o de Almeida (2002). Ao analisar empresas de economia de comunhão, o autor constrói a categoria denominada "modelo de negócios" que contempla os processos de hierarquia, divisão de trabalho, tomada de decisão e controle, processos que se mostram intimamente relacionados, o que representou uma alternativa para a pesquisa em empresas de pequeno porte. Entre as inovações, podemos destacar, além do supracitado modelo de negócios, rubricas tais como valores empresariais, relacionamento, motivação, desenvolvimento institucional, recrutamento e promoção, estrutura de incentivos, estratificação social, diferenciação, educação, estilo de liderança. O segundo estudo é o de Valeriano (2006), o qual promove uma inovação importante no quadro de análise original: o autor analisa a racionalidade nas onze categorias, mas suprime a divisão rígida entre as categorias no tocante aos elementos específicos de cada tipo de racionalidade; ao fazê-lo, Valeriano (2006) afirma que supera a dificuldade gerada pelo quadro original quando o pesquisador se depara com a análise da ação grupal e da ação individual. O terceiro estudo é o de Nava Hey (2008). A autora empreende o exame do processo de formação do administrador e, ao analisar a racionalidade subjacente, ela mantém a categoria valores, acrescentando mais três categorias/rubricas, a saber, as práticas de interação, as práticas metodológicas e as práticas de conclusão de curso. Dentro de cada uma dessas novas rubricas, a autora identificou os elementos de racionalidade também baseados no estudo original de Serva (1996).

Os seguintes estudos promoveram a supressão de algumas categorias tanto para adequar a análise aos objetivos e organizações enfocadas na pesquisa, como para viabilizar a elaboração do trabalho em tempo hábil. Assim, o estudo de Pinheiro (2003) se concentrou nas categorias analíticas hierarquia e tomada de decisão. O trabalho de Ferreira (2004) reteve as categorias processo decisório, normas e comunicação. A pesquisa de Tonet (2004) empreendeu a análise da racionalidade por meio das categorias satisfação individual, valores e objetivos. O estudo de Mudrey (2006) focalizou as categorias hierarquia e normas, valores e objetivos, ação social e relações ambientais. Silva (2007) trabalhou as categorias valores e objetivos, reflexão sobre a organização, dimensão simbólica, ação social e relações ambientais. Aguiar (2009) analisou o processo de tomada de decisão, as formas de comunicação, missão e valores, relações ambientais, hierarquia, controle, divisão do trabalho e ação social.

Caracterizados brevemente os trabalhos que fazem parte do que aqui denominamos primeira geração de estudos sobre a racionalidade, apresentamos agora a subclassificação elaborada por Santos (2012) que 
distribuiu os trabalhos da primeira geração em três grupos que melhor sintetizam os seus avanços, conforme quadro 3 a seguir. Ressaltamos que este quadro foi completado com as novas pesquisas identificadas após sua publicação.

Quadro 3

Perfil dos trabalhos da primeira geração de estudos sobre a racionalidade

\begin{tabular}{|c|c|c|}
\hline GRUPO & CONSIDERAÇÕES & $\begin{array}{l}\text { OBJETO DE } \\
\text { ANÁLISE }\end{array}$ \\
\hline $\begin{array}{l}1 \text { - Aplicação do } \\
\text { quadro de análise: } \\
\text { 1998 - 2001 } \\
\text { Matta (1998) } \\
\text { Fraga (2000) } \\
\text { Pinto (2001) } \\
\text { Reis (2001) }\end{array}$ & $\begin{array}{l}\text { a) Pesquisas se destinavam somente a determinar a racionalidade } \\
\text { predominante; } \\
\text { b) Estudaram todos ou quase todos os processos/rubricas } \\
\text { organizacionais do modelo de Serva (1996); } \\
\text { c) Apresentação de alguns indícios de tensão entre as } \\
\text { racionalidades de maneira não sistemática. }\end{array}$ & $\begin{array}{l}\text { Organizações de } \\
\text { diversos tipos }\end{array}$ \\
\hline $\begin{array}{l}2 \text { - Aplicação do } \\
\text { quadro de análise } \\
\text { e novas teorias: } \\
2002 \text { - 2009 } \\
\text { Almeida (2002) } \\
\text { Dorneles (2003) } \\
\text { Pinheiro (2003) } \\
\text { Lins (2004) } \\
\text { Tonet (2004) } \\
\text { Ferreira (2004) } \\
\text { Valeriano (2006) } \\
\text { Mudrey (2006) } \\
\text { Rodrigues (2008) } \\
\text { Nava Hey (2008) } \\
\text { Aguiar (2009) }\end{array}$ & $\begin{array}{l}\text { a) Restrição de alguns processos e realização de adaptações } \\
\text { (inserção de novos elementos); } \\
\text { b) O estudo das fenonomias começa a se destacar. Existência } \\
\text { mútua da racionalidade substantiva e da racionalidade } \\
\text { instrumental em um mesmo processo organizacional; } \\
\text { c) Indícios mais claros da existência da tensão e algumas } \\
\text { hipóteses. }\end{array}$ & $\begin{array}{l}\text { Organizações de } \\
\text { setores } \\
\text { específicos: } \\
\text { Economia de } \\
\text { Comunhão; } \\
\text { Economia da } \\
\text { Dádiva; } \\
\text { Economia Plural; } \\
\text { Economia } \\
\text { Solidária; } \\
\text { Fenonomias; } \\
\text { Autogestão; } \\
\text { Cursos } \\
\text { universitários. }\end{array}$ \\
\hline $\begin{array}{l}3 \text { - Aplicação do } \\
\text { quadro de análise, } \\
\text { novas teorias e } \\
\text { sinalização da } \\
\text { transição para } \\
\text { segunda geração: } \\
2006 \text { - 2010 } \\
\text { Ramos (2006) } \\
\text { Silva (2007) } \\
\text { Dias (2009) } \\
\text { Besen (2010) } \\
\text { Leal (2013) }\end{array}$ & $\begin{array}{l}\text { a) As considerações dos trabalhos anteriores começam a ser } \\
\text { observadas; } \\
\text { b) Insere-se o objetivo de ampliar as propostas apresentadas nos } \\
\text { estudos anteriores; } \\
\text { c) Tensão aparece pela primeira vez como elemento de estudo, } \\
\text { porém de forma não sistemática. Fortes indícios de tensão; } \\
\text { d) Possibilidade de gestão a partir da racionalidade substantiva; } \\
\text { e) Abre-se espaço para o início da segunda geração de estudos } \\
\text { sobre a racionalidade nas organizações. }\end{array}$ & $\begin{array}{l}\text { Processos } \\
\text { organizacionais }\end{array}$ \\
\hline
\end{tabular}

Fonte: Adaptado de Santos (2012). 
O primeiro grupo é representado por aqueles trabalhos de pesquisadores que se dedicaram a replicar o modelo de Serva (1996), comprovando sua possibilidade de aplicação nas organizações devido à utilização de praticamente todos os onze processos. Sobre as formas organizacionais, destaca-se o Terceiro Setor como um frequente terreno de estudos.

O segundo grupo é composto por trabalhos que trouxeram diferentes abordagens do campo de conhecimento da administração e áreas afins para dialogarem com as formulações de Guerreiro Ramos e de Habermas. A aproximação com diferentes fontes de conhecimento amplia as possibilidades de aplicação e promove um consequente refinamento no modelo de análise destinado à observação específica de uma quantidade menor de processos, bem como voltado para a análise do tipo organizacional escolhido.

O terceiro e último grupo apresentado no quadro 2 dá continuidade às características do segundo, mas se aprofunda na análise de poucos processos (geralmente dois ou três); apresenta um destaque para o tema da tensão entre as racionalidades; sinaliza a adoção dos trabalhos anteriores como uma fonte valiosa de indicações de pesquisas e elementos que poderiam ser incluídos nas pesquisas posteriores. Também se destaca um novo olhar para a gestão, no qual é identificada a possibilidade de se adotarem ações substantivas numa gestão que busque a eficácia e a efetividade. $\mathrm{O}$ advento deste terceiro conjunto de trabalhos representa o indício da transição para a segunda geração de estudos.

Quanto ao tema da tensão entre as racionalidades, ele começa a aparecer e a se destacar no terceiro grupo da primeira geração, particularmente nos trabalhos de Ramos (2006) e Leal (2013). Ramos (2006) teve como objetivo a análise da tensão na avaliação de projetos sociais de organizações do Terceiro Setor. Cumpre-nos destacar aqui a inquietação que o levou a estudar esse aspecto. Ramos (2006) constatou que o campo de atuação das organizações não governamentais sofre influências de outros setores, como o governamental e da iniciativa privada, o que acabou por introduzir no Terceiro Setor aspectos de uma gestão mais instrumental. Seu estudo demonstrou e comprovou que algumas práticas instrumentais são necessárias à gestão das organizações do Terceiro Setor, pois ainda vivemos numa sociedade na qual a lógica mercadológica predomina. Entretanto, há um conflito ético e administrativo na forma como esse processo ocorre. Cabe aos gestores terem a habilidade de lidar com a tensão causada entre a presença da racionalidade substantiva e também da racionalidade instrumental na gestão - observando a dinâmica específica exigida em cada organização.

Leal (2013), apoiado principalmente na Teoria Organizacional Substantiva proposta por Guerreiro Ramos, buscou compreender como a dinâmica entre a racionalidade instrumental e substantiva se manifestavam em um Clube de Xadrez, tanto na dimensão das relações internas da organização (nível organizacional) quanto na percepção particular de cada membro a respeito do jogo de xadrez (nível do indivíduo). A partir de seu estudo, o autor percebeu que, em relação às motivações individuais, o xadrez pareceu se mostrar como uma atividade de grande potencial autogratificante, embora imerso numa relação de completa imbricação entre racionalidades. $\mathrm{O}$ autor constatou também a grande motivação na busca pela vitória em cada partida, evidenciando que cada decisão ao longo de um jogo compõe um processo misto de instrumentalidade e "substantividade". Nesta perspectiva, a tensão foi vista mais como um conflito entre valores estéticos e resultado final. Já na perspectiva organizacional, percebeu-se que as motivações individuais têm influência nas relações entre os membros, porém não em uma relação de causa e efeito direta, pois o prazer na interação com outros colegas se mostrou mais marcante do que os componentes instrumentais das relações. Assim, Leal (2013, p. 132) finalizou seu trabalho destacando sua percepção de que "boa parte das ações realizadas dentro desse espaço possuem um misto entre instrumental e substantivo, sendo o fim predominantemente determinado pelos valores (sendo aqui, os valores determinados por atributos éticos) e os meios para seu alcance sistematizados de forma instrumental, numa combinação, ainda que tensa, mas de reciprocidade entre racionalidades".

A análise dos trabalhos que compõem a primeira geração traz indicações de diferentes possibilidades de espaços para a investigação da racionalidade substantiva. De maneira geral, os trabalhos foram unânimes no objetivo de apontar para o predomínio de uma racionalidade em detrimento de outra. Assim, os resultados 
destas pesquisas corroboram a proposição de Serva (1996), demonstrando na prática a coexistência entre as duas lógicas, na qual, para cada processo, uma lógica racional supera a outra no período da pesquisa; portanto as duas coexistem no mesmo contexto organizacional. Por este motivo, mesmo os estudos realizados em organizações privadas puderam contribuir e evidenciar a existência de elementos da racionalidade substantiva em algumas de suas práticas de gestão, como no trabalho de Fraga (2000) em uma empresa de montagem industrial; no estudo de Almeida (2002) em empresas partícipes da rede de economia de comunhão; no trabalho de Mudrey (2006) em uma escola privada; e na pesquisa de Dias (2009) em empresas do setor elétrico.

Contudo, alguns trabalhos foram conduzidos na perspectiva de que em organizações cuja forma jurídica sugeriria a existência de práticas mais democráticas - tais como as organizações do Terceiro Setor e as cooperativas - seria possível evidenciar os elementos da racionalidade substantiva muito mais fortalecidos. Entretanto, tal hipótese pode ser equivocada e reanalisada, quando vemos nos resultados de outros trabalhos nos quais algumas organizações, inicialmente pensadas como substantivas, demonstraram práticas semelhantes às empresas de mercado, e que a racionalidade instrumental pode predominar em muitas das ações de gestão. Assim, no contraponto de crenças ingênuas sobre a racionalidade em organizações do Terceiro Setor, em geral, os trabalhos demonstraram como em algumas dessas organizações predomina a racionalidade instrumental, orientada pela lógica de mercado. Ainda assim, em organizações onde há o envolvimento real dos cooperados, trabalhadores e/ou voluntários foi possível identificar fortes indícios da lógica substantiva. Assim, podemos afirmar o fato de que o tipo ou forma jurídica da organização não determina necessariamente a racionalidade predominante na prática administrativa, confirmando a crítica elaborada por Serva (1997a) aos estudos que já no ponto de partida baseiam-se em crenças e/ou ideologias preestabelecidas.

Por conseguinte, para que os resultados de pesquisa possam ser validados e venham a contribuir no sentido de promover os estudos da racionalidade substantiva, é fundamental que o uso do modelo de análise esteja aliado a uma postura crítica e analítica do pesquisador. Conforme Siqueira (2012), a abordagem do tema em questão requer do pesquisador uma espécie de "atitude parentética", superando o "plano existencial natural e ingênuo", para então estar habilitado a "desvincular-se de suas circunstâncias internas e externas", isto é, de pôr entre parênteses o eu e o mundo e a vivência do eu como tal, avaliando a realidade não como ela inicialmente pode se apresentar, mas com uma consciência crítica altamente desenvolvida. "Natural" é a atitude do homem "ajustado", despreocupado com a racionalidade noética e aprisionado em seu imediatismo. Já a atitude "crítica" suspende ou põe "entre parênteses" a crença no mundo comum, permitindo ao indivíduo atingir um nível de reflexão conceitual e, portanto, de liberdade (GUERREIRO RAMOS, 2001, p. 6-7).

O que está em debate aqui, especificamente, é uma dicotomia entre o modelo de análise e a análise propriamente dita. Por mais refinado e elaborado que seja o modelo, por mais didático e aplicável, ainda assim, é necessário que o pesquisador adote uma postura atenta e crítica. $\mathrm{O}$ modelo facilita a análise, mas não a substitui.

Após examinar detalhadamente os trabalhos mencionados, é possível concluir que a primeira geração de estudos validou o uso do modelo demonstrando empiricamente a presença e a importância da racionalidade substantiva na gestão de organizações produtivas. Por sua vez, os trabalhos seguintes, aqui denominados de segunda geração, trazem em seu escopo as contribuições da primeira geração e se propõem a aprofundar a investigação da racionalidade substantiva dentro dos diferentes processos de gestão de organizações produtivas.

\section{O início de uma segunda geração de estudos: aprendizagens e novos desafios}

Uma segunda geração dos estudos sobre a racionalidade na prática administrativa se inicia com o objetivo de extrair da primeira as principais contribuições ao campo de estudos e aprofundar as evidências da manifestação da racionalidade substantiva em processos específicos da gestão organizacional. Esta segunda geração consiste, assim, na busca pela sistematização da aprendizagem dos primeiros trabalhos, 
reconhecendo suas principais contribuições, desafios e metodologias, além de incluir novos aspectos e novos olhares sobre a racionalidade.

Esta nova vertente foi inaugurada com a pesquisa de Silva (2009), a qual sintetiza no que consiste esta nova geração de estudos:

O tema amadureceu no meio acadêmico e urge a necessidade de avançar nos objetivos. Sendo assim, a primeira geração tratou de examinar o tipo predominante de razão na prática administrativa, identificando as racionalidades nos processos de gestão, como também validando o modelo de identificação e análise dessas racionalidades proposto por Serva. Cabe agora fazer o campo evoluir com uma segunda geração de estudos sobre a racionalidade no sentido de codificar e sistematizar a aprendizagem, aprofundando o conhecimento de cada processo (SILVA, 2009, p. 17-8).

Com o objetivo de colaborar com a segunda geração de trabalhos sobre o tema da racionalidade substantiva que se inaugurava, Silva (2009) pesquisou e referenciou os estudos da primeira geração. A partir dos resultados desses trabalhos, a autora encontrou subsídios para a formulação de sete novas categorias de análise para o aprofundamento da investigação do processo de tomada de decisão em organizações substantivas. Tomando tais resultados como referência, Silva (2009) realizou uma pesquisa de cunho qualitativo e analisou o processo de tomada de decisão em duas instituições de tratamento oncológico infanto-juvenil da cidade de Natal: Grupo de Apoio à Criança com Câncer, e a Casa de Apoio à Criança com Câncer Durval Paiva, sendo que uma das instituições já havia sido analisada no trabalho de Lins (2004).

Os resultados do trabalho de Silva (2009) contribuíram para uma análise aprofundada do processo de tomada de decisão sob o prisma da racionalidade substantiva. A autora assumiu o desafio de construir novas categorias relacionadas a um processo específico do modelo de análise, aprofundando nestas subcategorias do processo a análise da racionalidade substantiva, como também o desafio de iniciar a absorção dos resultados dos estudos antecedentes que também utilizaram o modelo elaborado por Serva. Semelhantemente a Silva (2009), o estudo de Caitano (2010) teve como objetivo contribuir para a consolidação da segunda geração de estudos por meio da verificação da racionalidade substantiva no processo de reflexão sobre a organização e no processo de comunicação e relações interpessoais em uma organização da sociedade civil (CAITANO, 2010). A autora empreendeu uma análise aprofundada desses processos em uma organização comunitária do Terceiro Setor situada em Florianópolis. Para tanto, buscou nas análises de Serva, bem como nos estudos posteriores, identificar processos organizacionais que puderam de forma efetiva proporcionar à organização estudada o caráter emancipatório e substantivo. Na revisão dos resultados da primeira geração, Caitano (2010) observou que alguns dos processos administrativos, por serem totalmente fundamentados em bases instrumentais - oriundas das teorias clássicas da administração -, preservam sua natureza predominantemente utilitária. Por este motivo, mesmo quando identificados em organizações que no seu âmago instituem valores emancipatórios e que estes processos ainda que se mostrassem orientados para o entendimento, mantiveram preservados os elementos utilitários constituintes. Caitano (2010) percebe que alguns dos processos, classificados originalmente como secundários por Serva (1996), demonstraram ser fundamentais e característicos das organizações consideradas como "substantivas". Um destes processos organizacionais, tomado especificamente nesse estudo, foi o de reflexão sobre a organização.

O trabalho de Santos (2012) parte do delineamento dos estudos da segunda geração, buscando aprofundar o estudo da racionalidade nas seguintes rubricas: processo decisório e valores e objetivos individuais. O objetivo da autora foi identificar situações que promovem a tensão entre a racionalidade substantiva e a racionalidade instrumental nas práticas administrativas de gestores públicos e como estes respondem a essas situações. Esse trabalho parte de uma nova vertente que trouxe como elementos: o olhar para a tensão entre as racionalidades; o âmbito de análise na gestão pública; um diferente plano de análise que levasse em consideração, sobretudo, o olhar para o gestor público, ou seja, o estudo da racionalidade sob o ponto de vista de indivíduos inseridos em organizações. 
Santos (2012) identificou que o contexto da gestão pública não se constituiu em locus de estudo de nenhum dos trabalhos anteriores, como também nenhum deles se dedicou à análise individual, isto é, do gestor como ator que vivencia a tensão entre racionalidades. A autora considerou em seu trabalho que a gestão pública seria composta por uma orientação racional instrumental (voltada predominantemente para a eficácia e para a eficiência), de um lado, e uma orientação política (que considera questões de valores e visa promover o interesse público), de outro lado. Esta dubiedade de orientações poderia manifestar elementos de tensão nas lógicas de ação. Por reconhecer a participação do gestor neste processo, a pesquisadora entendeu que a tensão estaria vinculada diretamente às suas ações e manifestava-se por meio de concepções e comportamentos do gestor. A fim de captar esta percepção do indivíduo, o gestor, a autora adota a fenomenologia como método de investigação, sendo utilizada a técnica de entrevista em profundidade com gestores de duas instituições públicas de ensino.

Neste mesmo horizonte de pesquisa, o trabalho de Siqueira (2012) teve como objetivo compreender as manifestações da tensão entre as racionalidades substantiva e instrumental no processo de comunicação e relações interpessoais na gestão da Ecovila Itapeba, situada no litoral sul da Bahia. Siqueira (2012) inova, ao introduzir um estudo de caso sobre um tipo de organização específico, uma ecovila, tentando compreender como os membros de uma dessas organizações dão significado à tensão, de que forma os gestores lidam com esta tensão e de que forma os sujeitos respondem à mesma. Uma das mais importantes contribuições do estudo de Siqueira (2012) para o campo de estudos em questão foi a utilização do método etnográfico, por meio de observação participante. Para cumprir com este desafio, o autor habitou na ecovila durante quatro meses, vivenciando as experiências da comunidade e coletando suas impressões em um diário de campo.

Os estudos de Santos (2012) e de Siqueira (2012) introduzem claramente o elemento da tensão no modelo de análise dos dados de campo. A tensão, no estudo de Siqueira (2012), foi vista inicialmente como um símbolo linguístico empregado com frequência por Guerreiro Ramos (1981) para se referir à interação entre racionalidade instrumental e substantiva. Nesse sentido, ela foi entendida como em uma área intermediária da realidade onde a existência humana acontece, o "in-between" entre divino e humano, perfeição e imperfeição, razão e paixões inferiores, conhecimento e ignorância, imortalidade e mortalidade, pessoa humana e sociedade, indivíduo e organização, razão instrumental e razão substantiva (SIQUEIRA, 2012).

Assim, os estudos da segunda geração estão assumindo o desafio de aprofundar o conhecimento da relação complexa entre as racionalidades no cenário organizacional. Contudo, o aprofundamento constatado não preenche todas as lacunas que o próprio avanço das pesquisas, aliado à ignorância patente do ser humano sobre si mesmo, ensejam. Neste sentido, é forçoso que reconheçamos as limitações do conhecimento que estamos construindo neste campo de estudos. A racionalidade é e continuará a ser por longo tempo uma dimensão do indivíduo e da ação coletiva em que a ciência e a filosofia terão sempre muito a conhecer. Dentre as limitações que nos afetam no estágio em que nos encontramos, gostaríamos de indicar aquela que julgamos a mais importante: a não consideração plena da dimensão emocional na compreensão da racionalidade.

Ao analisar o trabalho do pesquisador, Bulgacov e Vizeu (2010) já abordaram e defenderam a indissociabilidade do binômio emoção-razão na construção do conhecimento. Contudo, além desse aspecto, o que estamos aqui enfatizando é a lacuna gerada pela não consideração do papel das emoções e sentimentos na racionalidade no campo de estudos que ora fazemos um balanço. O estágio de aprofundamento do conhecimento sobre a dimensão emocional na racionalidade permanece inédito nos estudos organizacionais. Obras como a de Damásio $(2009 ; 2010)$ no campo da neurociência, bem como a instauração de uma sociologia das emoções (STETS e TURNER, 2007; LEWIS, HAVILAND-JONES, BARRET et al., 2008) abrem novas perspectivas interdisciplinares para a compreensão da racionalidade enquanto fenômeno digno de estudo nas organizações. Portanto, ao reconhecermos essa limitação do campo de estudos aqui analisado, indicamos a construção de protocolos de pesquisa que contemplem as emoções e os sentimentos como uma lacuna e um possível desafio aos pesquisadores nesse campo. 


\section{Os estudos da racionalidade em periódicos nacionais do campo da administração}

Nesta sequência de análise serão apresentados os principais resultados da pesquisa realizada nos periódicos nacionais do campo da administração, perfazendo ao todo quatorze artigos que obedeceram todos os critérios estabelecidos, sendo doze de periódicos A2 e dois de periódicos B1.

Iniciamos a apresentação dos periódicos classificados pelo qualis da CAPES como A2, pela Revista de Administração de Empresas - RAE. A pesquisa realizada no website da revista RAE indicou um total de seis artigos sobre o tema, dos quais um é o próprio artigo de Serva, publicado em 1997. Outros dois artigos tratam do tema da racionalidade, porém sob o enfoque financeiro, e três artigos se enquadraram plenamente dentro da perspectiva selecionada.

A publicação mais recente sobre o tema na revista RAE é de 2012, cuja autoria é de Sérgio Sampaio Bezerra e Marcelo Milano Falcão Vieira, intitulada "Pessoa com deficiência intelectual: a nova "ralé" das organizações do trabalho". O artigo traz uma análise sobre a promoção da igualdade de oportunidade para trabalhadores com deficiência intelectual nas organizações modernas, tomada do ponto de vista da racionalidade como orientadora das suas práticas. A análise da racionalidade instrumental e substantiva é utilizada como pano de fundo para discutir os critérios de promoção desta igualdade, para isso os autores tomam por base a visão de Guerreiro Ramos (1981) sobre o tema, fazendo menção às contribuições do trabalho de Serva (1997) na análise da racionalidade nas organizações e se valem de algumas definições cunhadas por este autor.

O artigo de Souza e Carrieri (2011), publicado pela mesma Revista e intitulado "Racionalidades no fazer artístico: estudando a perspectiva de um grupo de teatro", teve por objetivo discutir quais tipos de racionalidade orientam a prática artística contemporânea. $\mathrm{O}$ trabalho toma por base toda a definição clássica de racionalidade a partir do conceito weberiano e dos autores da Escola de Frankfurt, trazendo também algumas definições de Guerreiro Ramos (1981). Ainda que não mencione claramente os estudos de Serva (1997a; 1997b) sobre o tema, os autores tomam por base o artigo de Vizeu (2005) e o de Boeira e Mudrey (2010), os quais referenciam o trabalho de Serva (1997a).

O artigo publicado por Vizeu (2005), “A ação comunicativa e estudos organizacionais", faz uma análise do diálogo entre a Teoria da Ação Comunicativa - TAC e os estudos organizacionais e trata do tema sob a perspectiva habermasiana, não se aprofundando nos estudos brasileiros. Ainda assim, Vizeu (2005) faz menção à relação da TAC com estudos de Guerreiro Ramos no Brasil e de seus seguidores, bem como também faz citação tanto a Guerreiro Ramos (1981) quanto a Serva (1996).

A busca realizada na RAE - Eletrônica indicou apenas o artigo de Lima, Hopfer e Souza-Lima (2004), intitulado: "Complementaridade entre racionalidades na construção da identidade profissional". Os autores fazem uma análise sobre a complementaridade entre as racionalidades instrumental e substantiva na identidade profissional médica. O estudo perpassa pelas definições do agir instrumental e substantivo em Habermas e Guerreiro Ramos (1981) e toma o estudo de Serva (1997) como referência de complementaridade entre as duas lógicas subjacentes ao agir.

A pesquisa realizada na Revista de Administração Contemporânea apresentou um total de dez artigos que atendiam aos critérios de busca; contudo, somente dois referem-se ao tema da racionalidade como tratamos aqui, ambos os artigos foram publicados no ano de 2012. O artigo de Andrade, Tolfo e Dellagnelo (2012), intitulado "Sentidos do trabalho e racionalidades instrumental e substantiva: interfaces entre a administração e a psicologia", traz uma aproximação entre os traços que caracterizam os sentidos atribuídos ao trabalho e as racionalidades instrumental e substantiva, com ênfase nos trabalhos publicados por Serva (1996; 1997a; 1997b). Embora não tenham aplicado o modelo de Serva, tomaram seus estudos como base para o desenvolvimento da pesquisa, bem como conceitos de Guerreiro Ramos (1981), o que possibilitou o desenvolvimento da concepção de sentidos do trabalho do tipo instrumental e do trabalho do tipo substantivo (ANDRADE, TOLFO e DELLAGNELO, 2012). 
Ainda na revista RAC, o artigo "Racionalidades em jogo em um processo de profissionalização", de Henrique Muzzio (2012), apresenta algumas especificidades envolvidas em um processo de profissionalização de uma empresa familiar de grande porte. $\mathrm{O}$ autor utiliza o antagonismo entre uma racionalidade instrumental, associada à visão de novos gestores profissionais, e uma racionalidade substantiva, vinculada à noção de antigos empregados, para discutir o espaço simbólico organizacional. Em sua análise utilizou o modelo de Serva (1996; 1997a; 1997b), com algumas adaptações.

A revista Organizações \& Sociedade apresentou um total de 24 artigos na busca por palavras-chave. Uma análise prévia destes artigos permitiu selecionar somente três que estavam diretamente relacionados com o tema aqui tratado. Os três artigos apresentaram resultados de dissertações da primeira geração de estudos sobre racionalidade, o estudo de Carvalho Dias (2009), Mudrey (2006), e o de Vizeu (2004).

A pesquisa de mestrado realizada por Carvalho Dias (2009) foi publicada em um artigo da revista Organizações \& Sociedade intitulado "Racionalidades Subjacentes às Ações de Responsabilidade Social Corporativa", de autoria de Carvalho Dias e Medeiros (2013). O artigo apresenta pesquisa que buscou entender a disseminação da responsabilidade social corporativa (RSC), sob a perspectiva das racionalidades instrumental e substantiva por meio de um estudo de múltiplos casos. Como uma de suas conclusões, os autores criaram um modelo de análise que pode ser utilizado para avaliar discursos sobre RSC em outros tipos de empresa e contextos.

O trabalho de dissertação de Mudrey (2006) deu origem ao artigo "Teoria da delimitação de sistemas sociais em duas unidades da Uni-Yôga", de autoria de Mudrey e Boeira (2010). Este artigo condensa os principais aspectos abordados numa dissertação cujo objetivo geral foi compreender como se manifestam os valores associados à racionalidade instrumental e à racionalidade substantiva na cultura de duas unidades da rede Uni-Yôga, com base na teoria da delimitação de sistemas sociais (GUERREIRO RAMOS, 1981).

Do mesmo modo, Vizeu (2004) também publicou os resultados de sua dissertação na mesma revista. O artigo "Da racionalidade instrumental à racionalidade comunicativa: o caso de uma instituição psiquiátrica" aborda a transição da racionalidade instrumental para a racionalidade comunicativa a partir do caso de um hospital psiquiátrico. Vizeu (2006) esclarece que seu trabalho segue a mesma linha de pesquisas empíricas sobre organizações substantivas, ou seja, as pesquisas classificadas aqui como primeira geração de estudos sobre a racionalidade que utilizam o modelo de Serva (1996; 1997a; 1997b) ou parte dele com adaptações.

O levantamento feito na Revista RAP - Revista de Administração Pública - indicou na busca preliminar por palavra-chave um total de doze artigos. A análise destas publicações demonstrou que apenas dois estavam diretamente relacionados ao tema. Os dois artigos publicados pela RAP que se referem aos estudos da racionalidade substantiva foram frutos de dissertações de mestrado já mencionadas anteriormente: "Empresas de economia de comunhão e razão substantiva", de Almeida e Leitão (2003), pertencente à primeira geração, e "Racionalidade substantiva no processo decisório", de autoria de Silva (2010), que faz parte da segunda geração.

A pesquisa ainda foi estendida para as revistas Brazilian Administration Review - BAR e Gestão \& Produção, cumprindo com os critérios estabelecidos no escopo metodológico. Entretanto, nestas revistas os instrumentos de busca não apontaram para artigos relacionados à temática e que pudessem ser objeto de nossa análise.

Na sequência, partimos para a análise dos periódicos classificados como B1, dos quais identificamos dezessete que se enquadram à área de estudo aqui tratada, classificados em três tipos: aqueles que não possuem artigos com a palavra-chave "racionalidade"; aqueles que possuem artigos, mas que não são apropriados aos demais critérios de análise; e aqueles que estão dentro dos critérios de busca definidos aqui.

Do total de dezessete periódicos, em três não foram encontrados artigos com as palavras-chaves definidas para a busca, sendo eles: Faces: Revista de Administração, Gestão \& Regionalidade e Revista Brasileira de 
Gestão Urbana. Em treze periódicos, apresentados no quadro 4 abaixo, foram encontrados artigos com palavras-chave definidas para nossa busca, mas que não atendiam aos demais critérios, ou seja, não referenciavam o modelo de Serva (1997a, 1997b), ou utilizavam seu quadro de análise para o estudo empírico da racionalidade nas organizações.

Quadro 4

Periódicos analisados - B1

\begin{tabular}{|l|l|}
\hline PERIÓDICO & QUANTIDADE \\
\hline Base (São Leopoldo. Online) & 1 artigo \\
\hline Caderno CRH (Online) & 4 artigos \\
\hline Cadernos EBAPE.BR & 9 artigos \\
\hline Civitas: Revista de Ciências Sociais (Impresso) & 4 artigos \\
\hline RAI: Revista de Administração e Inovação & 1 artigo \\
\hline $\begin{array}{l}\text { REAd. Revista Eletrônica de Administração (Porto } \\
\text { Alegre. Online) }\end{array}$ & 3 artigos \\
\hline Revista Brasileira de Ciências Sociais (Impresso) & 17 artigos \\
\hline Revista de Administração da UFSM & 2 artigos \\
\hline Revista de administração da Unimep & 2 artigos \\
\hline Revista de Ciências da Administração & 6 artigos \\
\hline Revista de Sociologia e Política (UFPR. Impresso) & 8 artigos \\
\hline Sociedade e Estado (UnB. Impresso) & 13 artigos \\
\hline Teoria \& Sociedade (UFMG) & 1 artigos \\
\hline
\end{tabular}

Fonte: Elaborado pelos autores.

Embora estes periódicos não se enquadrem nos critérios de análise, conforme já mencionado, eles apresentam artigos, sobretudo teóricos, que discutem a racionalidade sob o ponto de vista de outros autores e campos de estudo, enriquecendo e muito as pesquisas sobre racionalidade. Destacamos, sob esta ótica, quatro periódicos. A Revista Sociedade e Estado traz treze artigos sobre a racionalidade associando, principalmente, à sociologia econômica. A Revista Brasileira de Ciências Sociais que apresentou dezessete artigos teóricos e empíricos com discussões sobre a racionalidade segundo a perspectiva de diferentes autores. A Revista de Sociologia e Política que aborda a racionalidade sob a perspectiva da democracia e política. Por fim, o Cadernos EBAPE.BR, onde foram encontrados nove artigos com a palavra-chave "racionalidade" que, embora não se enquadrem nos critérios de pesquisa, tratam de temas que discutem uma nova abordagem de teoria das organizações a partir de uma perspectiva crítica e discutem o tema da racionalidade sob a perspectiva de autores como Guerreiro Ramos, Cornelius Castoriadis, Jürgen Habermas, Enrique Leff, Max Weber, entre outros. 
A Revista de Administração Mackenzie foi a que apresentou artigos que preenchiam os critérios de busca. Foram encontrados doze artigos com a palavra-chave racionalidade, dos quais dois contemplam todos os critérios. O primeiro é o estudo de Vizeu (2011), intitulado "Uma aproximação entre liderança transformacional e teoria da ação comunicativa". Neste trabalho, o autor considerou que a teoria da ação comunicativa provê uma análise crítica da liderança transformacional e, para auxiliar a fundamentar seus argumentos, utiliza evidências levantadas em estudos empíricos realizados por pesquisadores brasileiros, entre eles, o trabalho de Serva (1997). O artigo "A citricultura orgânica na região do Vale do Caí (RS): racionalidade substantiva ou instrumental?" (SEVERO e PEDROZO, 2008) teve como objetivo verificar se agricultores orgânicos de uma cooperativa, ao decidirem pelo cultivo orgânico, estavam mais inclinados a uma motivação substantiva ou instrumental e, por conseguinte, se a cooperativa poderia ser considerada uma organização substantiva ou não. Para tal, utilizou-se o modelo de Serva e as proposta de organizações substantivas de Guerreiro Ramos (1981). Ao término do estudo, os autores caracterizaram a cooperativa como uma organização substantiva de intensidade elevada.

\section{Conclusões}

Este artigo perfaz um levantamento preciso dos principais estudos empíricos realizados no Brasil desde os anos 90 sobre a racionalidade substantiva nas organizações que utilizaram o modelo de análise da racionalidade na gestão de organizações proposto por Serva $(1996 ; 1997 a ; 1997 b)$ e inspirado diretamente no pensamento de Alberto Guerreiro Ramos. Os resultados permitiram concluir sobre as significativas contribuições dos diversos trabalhos produzidos a partir da publicação do modelo de análise mencionado. Foram analisados vinte e quatro dissertações e quatorze artigos, somando trinta e oito estudos desenvolvidos em uma diversidade de organizações situadas em quase todas as regiões do país. A respeito das contribuições da análise desses trabalhos, é importante destacar a metodologia empregada nesses estudos. Os resultados demonstraram o uso de métodos de coleta e análise de dados diversificados, indicando viabilidade no uso de análise de conteúdo, métodos quantitativos em etapas preliminares e, principalmente, validaram o uso da observação (participante ou não), aliada a uma postura etnográfica por parte do pesquisador. As adaptações do modelo de análise também se mostraram pertinentes, adequando alguns destes trabalhos a objetivos específicos, que extrapolavam a investigação da racionalidade predominante, ou ainda, adequando o modelo à realidade das organizações pesquisadas. A integração do modelo a outros constructos teóricos também produziu resultados promissores.

O recurso analítico da classificação dos estudos em duas gerações revelou a sua importância. Mediante o emprego desse recurso foi possível perceber que: a) a primeira geração de pesquisas empíricas buscava, sobretudo, identificar a predominância de uma dada racionalidade na gestão; b) a segunda geração de estudos dá passos adiante: enriquece a sua fundamentação teórica pelo acréscimo do conhecimento produzido pela primeira geração e também vai mais além da identificação da predominância, assumindo como desafio a análise da relação complexa entre as racionalidades, como é o caso da tensão tanto no âmbito da ação coletiva como no âmbito da vivência do gestor. A atenção conferida à relação complexa entre as racionalidades, em especial à tensão entre elas, nos remete à importância da dimensão pragmática dos estudos da racionalidade aqui discutidos. Partindo do princípio da elaboração de tipos ideais que marcou os estudos de Weber e também de Guerreiro Ramos, a iniciativa de compreender as práticas de gestão sob o prisma da racionalidade aprofunda na segunda geração de estudos aqui indicada a dinâmica de racionalidades imbricadas na ação. Neste sentido, ao abordar a tensão, a segunda geração parece empreender uma aproximação cada vez maior daquilo que Lima e Teixeira (1994) denominaram "cotidiano administrativo".

Em seu conjunto, os estudos validaram as principais proposições de Serva (1996; 1997a; 1997b): a coexistência de diferentes racionalidades na gestão de organizações e, por conseguinte, a constatação de uma tensão entre a lógica de ação instrumental e a lógica de ação substantiva no cotidiano dessas organizações e 
dos seus atores. Esses trabalhos permitem concluir que o campo de estudos iniciado por Guerreiro Ramos vem se consolidando e ensejando o desenvolvimento de pesquisas no âmbito dos estudos organizacionais no Brasil, servindo de recurso teórico-metodológico nas investigações da racionalidade substantiva na gestão.

O levantamento das publicações sobre o tema nos principais periódicos nacionais reforçou ainda mais a contribuição do estudo de Serva (1997a; 1997b), bem como de alguns dos estudos posteriores. Tal afirmação é sustentada na medida em que um expressivo número de artigos publicados nestes periódicos de importância reconhecida teve por base os estudos de Serva (1997a; 1997b) ou estudos posteriores como referência na discussão em torno da racionalidade nas organizações.

Partindo da constatação de que os resultados da pesquisa publicada na segunda metade dos anos 90 se mostraram válidos e passíveis de observação em outras organizações, cumpre agora dar continuidade ao próximo passo para o avanço no campo dos estudos sobre a racionalidade substantiva.

Neste sentido, os estudos de Silva (2009), Caitano (2010), Santos (2012) e Siqueira (2012) sugerem o aprofundamento em alguns dos processos organizacionais para construir categorias de análise próprias e investigar a racionalidade subjacente, como também levam em conta as contribuições e descobertas dos estudos anteriores, numa efetiva perspectiva de campo de estudos. Esta possibilidade parece promissora, especialmente porque permite ampliar o conhecimento científico no campo dos processos de gestão sob uma abordagem racional substantiva.

Nossa expectativa é de que este artigo represente uma parcela de contribuição para o campo dos estudos organizacionais, indicando e apresentando em que estágio se encontram os estudos sobre racionalidade, especialmente para os pesquisadores que se sentem atraídos pela possibilidade de realizar pesquisas no tema em questão. Por conseguinte, gostaríamos de inferir sobre duas direções (dentre as várias possíveis) que nos parecem procedentes para o que poderia talvez serem denominados "estudos de terceira geração": a primeira refere-se à absorção do tema da emoção no estudo da racionalidade. Como indicamos acima, as pesquisas em neurociência desenvolvidas principalmente por Damásio $(2009 ; 2010)$ e o aprofundamento de uma sociologia das emoções (STETS e TURNER, 2007; LEWIS, HAVILAND-JONES, BARRET et al., 2008) podem promover um grande avanço ao campo em questão; a segunda direção vai ao encontro mais efetivo das chamadas "teorias da ação" em pleno desenvolvimento nas ciências sociais, com destaque para a sociologia pragmática (BOLTANSKI e THÉVENOT, 2001; BREVIGLIERE e STAVO-DEBAUGE, 1999). A aproximação com tais abordagens representaria uma alternativa à teoria da ação comunicativa de Habermas, certamente ampliando a compreensão do entrelaçamento das racionalidades na ação coletiva.

O desenvolvimento desse campo de estudos também pode ser alcançado pela via da ampliação dos objetos de análise, isto é, incorporando também objetos e aspectos que não compõem o modelo elaborado por Serva aqui discutido.

Finalizamos este trabalho apostando nas perspectivas da continuidade e do aprofundamento desses estudos, pois o que está em jogo para a vertente crítica que visa à emancipação humana é o enfrentamento do desafio de melhor compreender a gestão como parte importante da ação coletiva em grupos organizados. Assim procedendo, poderemos contribuir significativamente para a concretização do potencial implícito do campo de estudos iniciado brilhantemente por Guerreiro Ramos.

\section{Referências}

AGUIAR, S. A. de. Práticas cooperativas em redes de economia solidária sob a óptica da ação comunicativa: o caso da Rede Justa Trama. Dissertação (Mestrado). Fortaleza: UNIFOR, 2009. 
ALMEIDA, M. A. Empresas de economia de comunhão: possibilidade de valorização da racionalidade substantiva na organização econômica? Dissertação (Mestrado em Administração) - Pontifícia Universidade Católica. Rio de Janeiro, 2002.

ALMEIDA, M. A.; LEITÃo, S. P. Empresas de economia de comunhão e razão substantiva. Rev. Adm. Pública, v. 37, n. 6, p. 1145-1170, 2003.

ANDION, C.; SERVA, M. A Etnografia e os estudos organizacionais. In: GODOI, K. C. et al. (Orgs.). Pesquisa Qualitativa em Estudos Organizacionais: paradigmas, estratégias e métodos. São Paulo: Saraiva, 2006.

ANDRADE, S. P. C. de; TOLFO, S. R.; DELLAGNELO, E. H. L. Sentidos do trabalho e racionalidades instrumental e substantiva: interfaces entre a administração e a psicologia. Revista de Administração Contemporânea [online], v.16, n. 2, p. 200-216, 2012

BARRETO, C. Sobre a racionalidade humana: conceitos, dimensões e tendências. Anais do XVII ENANPAD, v. 9. Salvador, ANPAD, 1993.

BESEN, F. As fenonomias e a economia plural: O olhar da gestão na dimensão territorial. Dissertação (Mestrado em Administração) - Universidade Federal de Santa Catarina. Florianópolis, 2010.

BEZERRA, S. S.; VIEIRA, M. M. F.. Pessoa com deficiência intelectual: a nova "ralé" das organizações do trabalho. Revista de Administração de Empresas, São Paulo, v. 52, n. 2, p. 232-244, março/abril 2012.

BOEIRA, S. L.; MUDREY, D. Teoria da delimitação de sistemas sociais em duas unidades da Uni - Yoga. Organizações \& Sociedade, Salvador, v. 17, n. 52, p. 175-197, jan./mar. 2010.

BOLTANSKI, L. ; THÉVENOT, L. De la justification - les économies de la grandeur. Paris: Gallimard, 2001.

BREVIGLIERE, M.; STAVO-DEBAUGE, J. Le geste pragmatique de la sociologie française. Autour des travaux de Luc Boltanski et Laurent Thévenot. Antropolítica, n. 7, p. 7-22, 1999.

BULGACOV, Y.; VIZEU, F. A Positividade da Emoção na Prática Social da Pesquisa em Organizações. Encontro de Estudos Organizacionais, Florianópolis. VI Encontro de Estudos Organizacionais, 2010.

CAITANO, D. A racionalidade substantiva na gestão organizacional: contribuição para consolidação de um campo de estudos. Dissertação (Mestrado em Administração) - Universidade Federal de Santa Catarina. Florianópolis, 2010.

CALDAS, M. Explorando outros viveres: ensaio sobre a escolha e a diversidade em design organizacional. Anais do XVIII ENANPAD, v. 8. Curitiba, ANPAD, 1994.

CHANLAT, J. O indivíduo na organização: dimensões esquecidas. São Paulo: Atlas, 1996.

DAMÁSIO, A. Em busca de Espinosa: prazer e dor na ciência dos sentimentos. São Paulo: Companhia das Letras, 2009.

DAMÁSIO, A. O erro de Descartes: emoção, razão e cérebro humano. São Paulo: Companhia das Letras, 2010.

DELLAGNELO, E. Racionalidade e Novas Formas Organizacionais. In: LANER, A. S.; CRUZ JÚNIOR, J. B. Repensando as organizações. Florianópolis: Fundação Boiteux, 2004.

DIAS, C. Racionalidades subjacentes às ações de responsabilidade social corporativa em empresas do setor elétrico brasileiro. 2009. Dissertação (Mestrado em Administração) - Universidade de Brasília, Brasília, 2009.

DIAS, C.; MEDEIROS, J. Racionalidades subjacentes às ações de responsabilidade social corporativa. Organizações \& Sociedade, Salvador, v. 20, n. 64, p. 17-36, mar. 2013. 
DORNELES, S. B. Autogestão e racionalidade substantiva. Dissertação (Mestrado em Administração) Universidade Federal de Santa Catarina. Florianópolis, 2003.

FRAGA, M. A Empresa Produtiva e a Racionalidade Substantiva: A Teoria da Ação Comunicativa de Jürgen Habermas no Ambiente Organizacional integrativo: De Mary Parker Follett a Collins e Porras. Porto. Dissertação PPGA - UFRGS, 2000.

FREITAG, B. A teoria crítica: ontem e hoje. 4. ed. São Paulo: Brasiliense, 1986

GARCIA, R. A base de uma administração autodeterminada: o diagnóstico emancipador”. Revista de Administração de Empresas, v. 20, n. 2, p. 7-17, 1980.

GUERREIRO RAMOS, A. A nova ciência das organizações: uma reconceituação da riqueza das nações. Rio de Janeiro: FGV, 1981.

HABERMAS, J. Teoria de la acción comunicativa. v. I-II. Madrid: Taurus, 1987.

KALBERG, S. Max Weber's types of rationality: cornerstones for the analysis of rationalization process in history. American Journal of Sociology, v. 85, n. 5, p. 1145-1179, 1980.

KANT, I. Textos seletos. Petrópolis: Vozes, 2005.

LEAL, J. V. N. Análise da dinâmica entre racionalidade instrumental e substantiva na prática organizacional: estudo de caso no Clube de Xadrez de Florianópolis. 2013. 145 p. Dissertação (Mestrado) - Universidade Federal de Santa Catarina, Centro Socioeconômico, Programa de Pós-Graduação em Administração, Florianópolis, 2013.

LEWIS, M.; HAVILAND-JONES, J.; BARRET, L. (Orgs.). Handbook of emotions. New York: Gilford Press, 2008.

LIMA, J.; TEIXEIRA, A. O cotidiano administrativo de pequenos produtores de hortigranjeiros. In: Anais do XVIII ENANPAD. Curitiba, ANPAD, v. 4. 1994. 224-236 p.

LIMA, S. M. M. de; HOPFER, K. R.; SOUZA-LIMA, J. E. Complementaridade entre racionalidades na construção da identidade profissional. RAE - eletrônica, v. 3, n. 2, julho-dezembro 2004.

LINS, N. M. Articulação entre elementos da racionalidade instrumental e substantiva nos processos organizacionais da CACC Durval Paiva. Dissertação (Mestrado em Administração). Universidade Federal do Rio Grande do Norte, Natal, 2004.

MATTA, W. da. Pesquisa da racionalidade no Sistema Unimed da Bahia. Salvador. Dissertação de Mestrado, Escola de Administração da Universidade Federal da Bahia, 1998.

MUDREY, D. Racionalidade e valores: um estudo de caso em duas unidades da rede Uni- Yôga. Dissertação Universidade do Vale do Itajaí. Biguaçu: Univali, 2006.

MUZZIO, Henrique. Racionalidades em jogo em um processo de profissionalização organizacional. Revista de Administração Contemporânea [online], v.16, n. 6, p. 827-844, 2012.

NAVA HEY, L. A. Racionalidade instrumental e substantiva nas práticas de formação do administrador: um estudo de casos múltiplos junto a instituições de ensino em Curitiba. Dissertação (mestrado) - Universidade Positivo, 2008.

OLIVEIRA, F. A teoria crítica e a totalização da racionalidade instrumental ou pessimismo da Escola de Frankfurt. Anais do XVII ENANPAD, v. 9. Salvador, ANPAD, 1993.

PAES DE PAULA, A. P. Guerreiro Ramos: resgatando o pensamento de um sociólogo crítico das organizações. Organizações \& Sociedade, v. 14, n. 40, p. 169-188, 2007. 
PINHEIRO, D. Sustentabilidade social de uma organização da economia social: um estudo de caso na AFECE Associação Franciscana de Educação ao Cidadão Especial. Dissertação (Mestrado em Administração) - Universidade Federal do Paraná. Curitiba, 2003.

PINTO, W. Análise das práticas administrativas de uma fundação empresarial aberta. Dissertação. EBAP, Fundação Getulio Vargas, Rio de Janeiro, 2001.

PIZZA JÚNIOR, W. Razão substantiva. Rev. Adm. Pública, v. 28, n. 2, p. 7-14, abr./jun. 1994

RAMOS, M. Racionalidade nas organizações do Terceiro Setor: tensões e implicações para a avaliação de programas sociais. Brasília: Universidade de Brasília, 2006.

REIS, L. A racionalidade substantiva na avaliação de projetos em ONGs: três casos. Dissertação. EBAP, FGV, Rio de Janeiro, 2001

RODRIGUES, D. A racionalidade nas práticas administrativas das Cooperativas de trabalho: um estudo de caso em uma cooperativa de trabalho de Belo Horizonte. Dissertação de Mestrado em Administração. Faculdade Novos Horizontes, Belo Horizonte, 2008.

SANTOS, L. S. A Tensão entre a racionalidade substantiva e a racionalidade instrumental na gestão pública: novos caminhos de um campo de estudos. Florianópolis. Dissertação (Mestrado) - Universidade Federal de Santa Catarina. Programa de Pós-Graduação em Administração.

SERVA, M. Racionalidade e Organizações: o fenômeno das organizações substantivas. Volumes I e II. São Paulo: FGV, 1996. Tese de Doutorado em Administração, Escola de Administração de Empresas de São Paulo, Fundação Getulio Vargas, 1996.

SERVA, M. A Racionalidade substantiva demonstrada na prática administrativa. Revista de Administração de Empresas, São Paulo, v. 37, n. 2, p. 18-30, 1997a.

SERVA, M. Abordagem substantiva e ação comunicativa: uma complementaridade proveitosa para a teoria das organizações. Rev. Adm. Pública, v. 31, n. 2, p. 108-34, mar./abr. 1997 b.

SEVERO, L. S.; PEDROZO, E. A. A citricultura orgânica na região do Vale do Caí (RS): racionalidade substantiva ou instrumental? Revista de Administração Mackenzie, São Paulo, v. 9, n. 2, p. 58-81, abr. 2008.

SILVA, M. Racionalidade substantiva no processo decisório: um estudo em instituições que lidam com o tratamento oncológico infanto-juvenil na cidade de Natal-RN. Dissertação (Mestrado em Administração) - Universidade Federal do Rio Grande do Norte. Natal, 2009.

SILVA, M. Racionalidade substantiva no processo decisório: um estudo em instituições que lidam com o tratamento oncológico infanto juvenil na cidade de Natal (RN). Rev. Adm. Pública, v. 45, n. 5, p. 1327-1361, 2011.

SILVA, P. G. Sustentabilidade social: um estudo de caso no mosteiro Monte Carmelo. Dissertação (Mestrado em Administração) - Pontifícia Universidade Católica do Paraná, 2007.

SIQUEIRA, G. Tensão entre as racionalidades substantiva e instrumental na gestão de ecovilas: novas fronteiras do campo de estudos. Florianópolis, 2012. Dissertação (Mestrado) - Universidade Federal de Santa Catarina. Programa de Pós-Graduação em Administração.

SOUZA, M. P. S.; CARRIERI, A. P. Racionalidades no fazer artístico: estudando a perspectiva de um grupo de teatro. Revista de Administração de Empresas, São Paulo, v. 51, n. 4, p. 382-395, jul./ago. 2011.

STETS, J.; TURNER, J. Handbook of sociology of emotions. New York: Springer, 2007.

TENÓRIO, F. Tem razão a administração? Rev. Adm. Pública, v. 24, n. 2, p. 5-9, fev./abr. 1990. 
TONET, R. Fenonomias, economia plural e desenvolvimento local: um estudo na feira de artesanato em Curitiba PR. Dissertação (Mestrado em Administração) - Universidade Federal do Paraná. Curitiba, 2004.

VALERIANO, J. C. Racionalidade nas práticas administrativas de uma Cooperativa em Itabira/MG. Dissertação. FEAD. Belo Horizonte: FEAD- MINAS, 2006.

VASCONCELOS, F. Racionalidade, ética e organizações - uma visão analítica". Anais do XVII ENANPAD, v. 9. Salvador, ANPAD. 1993.

VIZEU, F. Organizações burocratizadas rumo à razão comunicativa: O caso de uma instituição psiquiátrica. Dissertação (Mestrado). Curso de Administração, UFPR, 2004.

VIZEU, F. A ação comunicativa e estudos organizacionais. Revista de Administração de Empresas, São Paulo, v. 45, n. 4, p. 10-21, out./dez. 2005.

VIZEU, F. Da Racionalidade Instrumental à Racionalidade Comunicativa: o caso de uma Instituição Psiquiátrica. Revista Organizações \& Sociedade, Salvador, v. 13, n. 36, p. 163-184, jan./mar. 2006.

VIZEU, F. Uma aproximação entre liderança transformacional e Teoria da Ação Comunicativa. Revista de Administração Mackenzie [Online], São Paulo, v. 12, n. 1, p. 53-81, feb. 2011.

WEBER, Max. Ensaios de sociologia e outros escritos. São Paulo: Abril Cultural, 1974. 